\title{
Causality between Monetary Expansion and the Price Level in India since 1950s - A Re-Examination
}

\author{
Sanjib Debnath and Ritwik Mazumder
}

\author{
Department of Economics, Assam University, Silchar, Assam 788011, India
}

\begin{abstract}
This paper has tested short run causality between broad money supply and whole-sale price index (WPI) in India during 1951-2013 adopting a Toda-Yamamoto (1995) modified Granger causality approach under a VAR environment. Exponentially detrended annual time series data on broad money supply and the whole-sale price index are used for this purpose. Alternative tests for structural breaks reveal significant but dissimilar breaks in the variables. The empirical results are suggestive of a uni-directional causality from broad money supply to WPI. The study further finds that broad money supply and WPI in India have a long-run co-integrating relationship and short run causal relations could hence be expected.
\end{abstract}

Keywords: Broad money supply, WPI, Modified Granger Causality, Toda-Yamamoto (1995) and VAR.

\section{INTRODUCTION}

Over the years, empirical studies on monetary expansion and inflation or between money supply and the price level have received significant attention in developing countries. This is perhaps because most of these nations today have a significant poor population and a burgeoning middle class and inflation hurts these groups the most. Consequently the key policy objective of both monetary and fiscal authorities in such countries is to control inflation (i.e., maintain price stability) without jeopardising the growth potentials. The monetary authorities truly recognise both the theoretical and empirical validities of money supply price level inter-linkage which compels them to adopt tighter monetary policies during periods of high inflation. Further welfare states are aware about the social and economic costs of inflation which motivate them to fix price stability as the primary goal of macroeconomic policy. Price volatility creates uncertainties, lowers the real returns to savings and investments, and is detrimental for economic growth.

The literature on money-inflation nexus in India recognizes that unwarranted growth of money supply has been one of the key factors behind the inflationary spells experienced since the 1950s. Monetary expansion or increase in money supply was triggered by central government borrowings from the Reserve Bank of India (Pattnaik and Samantaraya 2006; Reddy 1999). Indian economists maintain that the factor primarily accountable for the excessive growth of money supply and thus inflationary spells experienced in India, has been the large scale resort to deficit financing by the central government. This argument led

*Address of correspondence to this author at the Department of Economics, Assam University, Silchar, Assam 788011, India; Tel: 91-03842-270853;

Fax: 91-03842-270802; E-mail: r_itwikm@yahoo.com

JEL Classification: C32, E50, E52, E59. to the discontinuation of automatic monetisation of debt by the RBI since 1997. Among the significant empirical contributions in this area for the Indian economy in recent years, the studies by Rangarajan and Arif (1990), Jadav and Singh (1990), Srimany and Samanta (1998), Parida et al. (2001), Rangarajan (2001), D'Souza (2003), Mohan (2008), Mishra and Mishra (2009), Singh and Kalirajan (2006 and 2007) are important in view of their economic as well as methodological robustness. However short period analyses in the above studies may question the statistical reliability of the test results as because multiple business cycles across decades are not captured.

The present study however focuses entirely on testing for short run causality between broad money supply and whole-sale price index (WPI) in India during 1951-2013 adopting a Toda-Yamamoto (1995) modified Granger causality approach under a VAR environment. In particular the study examines whether broad money supply expansion has been inflationary in India. Exponentially detrended annual time series data on broad money supply and the whole-sale price index are used. Structural break unit root tests along with structural break dates are also determined. The paper is written in the following sections. After a brief introduction to issues relating to money-inflation nexus in India in section 1, data sources and econometric issues are discussed in section 2. Section 3 presents the analysis of empirical results, followed by a very brief summary and conclusions in section 4 .

\section{METHODOLOGY AND DATA}

\subsection{Variable Selection and Detrending}

The direction of causality between money and prices is justified by the monetarist school. The 
monetarist argument is that if money stock grows faster than GDP (or national income) then there will be an upward movement of the general price level (whole sale price index, for instance) which would lead to inflation. However if money supply rises in the long run in line with the general price level (in a co-integrated manner) then there would be no inflation. However, an unwarranted rise in the money supply would be inflationary.

According to the quantity equation, nominal value of aggregate expenditure on all final goods and services equals the nominal value of output. According to monetarists, velocity of money circulation may be taken as fixed in the short run due to several institutional reasons. Furthermore, long run out is fixed (inelastic aggregate supply) although short run fluctuations are possible. Thus an increase in the money supply will lead to an increase in the general price level causing inflation.

The study period is $1951-2013$ as annual broad money supply figures for India are available from 1951 onwards. This gives us 63 annual time point observations which is a typical macroeconomic long run. The variables considered are broad money supply (M3 which is M1 plus term deposits; M1 being narrow money defined as the sum of currency in circulation and demand deposits) and Whole-sale Price Index (WPI) with 2004-05 as the base year. The splicing method was applied to generate an uninterrupted WPI series at 2004 prices, as because the base period is shifted every ten years. The RBI publishes a conversion factor at the beginning of every new base period for converting new price index numbers in terms of the old base year. This, it must be admitted, is merely an approximation as because the commodity composition and respective weights used to compute WPI (and even CPI) changes across decades. Many commodities are deleted as they become irrelevant over time. The entire data set is compiled from Reserve Bank of India: Handbook of Statistics on the Indian Economy, 2014 available at the RBI website.

Long run macroeconomic data is most likely to have a trend - linear or non-linear. A glance at the time series line plots for each variable during 1951-2014 (not presented) reveals strong non-linear trends in all three variables. Both parabolic and exponential curves are fitted to each variable and the goodness of fit statistics are compared (see Table A1 of the Appendix). The results are strongly suggestive of exponential trends in each of the three variables. Accordingly, the exponentially detrended series on each variable are preferred for analysis. The detrended data is generated using the following steps. First, the natural logarithm of the variable is regressed linearly on a constant and time, i.e., the linear regression $\ln \left(y_{t}\right)=\ln (\alpha)+\beta . t+$ error, is run where $y_{t}$ is the variable to be detrended. This is a log-linear form of the exponential growth (or smoothing) function $y_{t}=\alpha \cdot \exp (\beta . t)$. Second, the parameters $\alpha$ and $\beta$ are estimated using OLS and predicted $\ln \left(y_{t}\right)$ series is generated. Third, anti-log of predicted $\ln \left(y_{t}\right)$ is generated, which is predicted $y_{t}$ in non-logarithmic form. Finally $e_{t}=y_{t}-\widehat{y_{t}}$ is the residual from the exponential smoothing (or curve fitting) in nonlogarithmic form and is thus the part of $y_{t}$ that is free from any exponential trend (where $\widehat{y}_{t}$ is predicted $y_{t}$ in non-logarithmic form). Hence, $e_{t}$ is exponentially detrended $y_{t}$. This method is applied to detrend both variables - broad money supply and WPI.

Standard tests for stationarity may be misleading for non-linearly trended data (for instance quadratic or exponential, both of which are rising at a rising rate over time) as because standard tests of stationarity such as Augmented Dickey-Fuller and Philips-Perron tests include linear trend terms only (i.e., some 'constant' times 'time'). For an exponentially growing variable, stationarity may not be attained even at second difference, although for de-trended series it may be attained either at level (if trend stationary) or at first difference. Moreover, the autocorrelation function (ACF) helps us to select the lag lengths $p$ (order of AR) and $q$ (order of MA) and the ACF of the residuals is an important diagnostic tool. Unfortunately ACF as used in linear models may be misleading for non-linear models. The reason is that autocorrelation coefficients measure the degree of linear association between $Y_{t}$ and $Y_{t-i}(Y$ is the time series variable in question). As such ACF may fail to detect important non-linear relationships in the data. It is thus desirable to work with detrended data.

\subsection{Testing Stationarity in the Presence of Structural Breaks}

In the long run macroeconomic variables are expected to experience structural breaks, some of which may be the result of macroeconomic policy shifts, regime changes, or random shocks (droughts, warfare, socio-political instability and violence, etc.) at the domestic level or due to similar factors at the international level. The present study applies the BaiPerron (1998 and 2003) multiple unknown structural break point test to original as well as the detrended series and compares the periods of break for each of 
the three variables. Instead of going into the mathematical details, the method of break date determination as performed using EVIEWS 9 is as follows. First the time series variable in question is regressed (using OLS) on a constant only allowing for serial correlation that varies across break dates (regimes) through the use of HAC covariance estimation. Three break dates are considered along with a trimming percentage of 20 , which implies around 12 observations per regime (as the period 1951-2914 implies 63 observations). Since the errors are assumed to be serially correlated, quadratic spectral kernel based HAC covariance estimation is specified using prewhitened residuals. The kernel bandwidth is determined automatically using the Andrews $A R(1)$ method. The default method setting in EVIEWS 9 (sequential $L+1$ breaks vs. $L$ ) instructs the software to perform sequential testing of $I+1$ versus/breaks using the methods outlined in Bai (1997) and Bai and Perron (1998). The error distribution is allowed to differ across breaks to allow for heterogeneity. This test employs the same HAC covariance settings as used in the original equation but assumes regime specific error distributions. The break dates along with the respective F-statistic values are presented in the results empirical section. Stationarity related issues are discussed next. The Bai-Perron 'Global break point vs. none' test is avoided.

Perhaps the most widely used unit root test to examine the stationarity of a time series (order of its integration) is the Augmented Dickey-Fuller test (ADF test) which makes use of equation (2.3.1). This generalised form includes both trend and intercept in the model.

$$
\Delta y_{t}=a_{0}+\gamma \cdot y_{t-1}+a_{1} \cdot t+\sum_{i=1}^{p} \beta_{i} \cdot \Delta y_{t-i}+\varepsilon_{t}(2.3 .1)
$$

Equation (2.3.1) tests the null hypothesis of a unit root against a trend stationary alternative. The optimum number of lagged $\Delta y_{t}$ terms (introduced to tackle serial correlations in the errors) may be determined by the optimum value of some information criterion such as Schwartz's Information Criterion (SIC). Phillips and Perron (1988) proposed a nonparametric method of controlling serial correlation while testing for unit root. They estimate the unaugmented Dickey-Fuller test equation [Equation (2.3.1) without the term ( $\sum_{i=1}^{p} \beta_{i} . \Delta y_{t-i}$ ) on the right hand side], and modifies the t-ratio of the $y$ coefficient so that serial correlation does not affect the asymptotic distribution of the test statistic.

Kwiatkowski, Phillips, Schmidt and Shin (1992) propose a test of the null hypothesis that the observed series is stationary around a deterministic trend. The series is expressed as the sum of deterministic trend, random walk and stationary error and the test is the LM test of the null hypothesis that the random walk has zero variance. The asymptotic distribution of the statistic is derived under the null and under the alternative that the series is difference stationary. KPSS test is quite contrary to the ADF and PP tests which consider the null hypothesis of unit root (i.e. a non-stationary series) as opposed to the former (KPSS) which considers a null hypothesis of stationary series.

The ADF and other traditional stationarity tests do not normally include a structural break term. But one can insert structural break dummies (say, seasonal dummies, for example) in equation (2.3.1) that may include both slope and intercept dummies. The point of break may be exogenously determined (approximately) by a visual scrutiny of the time series line plots. Importantly, the ADF test fails to perform well in the presence of structural breaks especially when the breaks are ignored. In such situations unit root tests with structural breaks are more suitable [see Perron (1989); Zivot and Andrews (1992)]. Perron (1989) demonstrated, assuming an exogenously fixed break date, that the power to reject the null hypothesis of unit root decreases (given that the alternative hypothesis of stationarity is actually true) when the structural break is ignored.

Zivot and Andrews (1992) suggest an improvement over the Perron (1989) test where they presume that the exact break point is unknown and endogenise the break date determination. A data dependent algorithm is used to proxy Perron's subjective procedure to determine the break points endogenously. Following Perron's characterization of the form of structural break, they adopt the following three models to test for unit roots.

$$
\begin{aligned}
& \Delta y_{t}=a_{0}+\gamma \cdot y_{t-1}+a_{1} \cdot t+\delta \cdot D U_{t}+\sum_{i=1}^{p} \beta_{i} \cdot \Delta y_{t-i}+\varepsilon_{t} \\
& \Delta y_{t}=a_{0}+\gamma \cdot y_{t-1}+a_{1} \cdot t+\theta \cdot D T_{t}+\sum_{i=1}^{p} \beta_{i} \cdot \Delta y_{t-i}+\varepsilon_{t} \quad \text { (Model A) } \\
& \Delta y_{t}=a_{0}+\gamma \cdot y_{t-1}+a_{1} \cdot t+\theta \cdot D U_{t}+\delta \cdot D T_{t}+\sum_{i=1}^{p} \beta_{i} \cdot \Delta y_{t-i}+\varepsilon_{t} \text { (Model C) }
\end{aligned}
$$

Here $D U_{t}$ captures mean shift occurring at each possible break-date (TB) while $D T_{t}$ is corresponding trend shift variable. Formally the values assigned to $D U_{t}$ and $D T_{t}$ may be summarised as follows. $D U_{t}=1$ for $t>T B$, and $=0$ otherwise. On the other hand $D T_{t}=t-T B$ for $t>T B$, and $=0$ otherwise. 
The null hypothesis in all three models is that $y=0$, which implies that $\left\{y_{t}\right\}$ has a unit root with drift without any structural break. The alternative hypothesis if $y<0$, implies that the series is a trend-stationary with a single break occurring at some unknown time point. Zivot and Andrews regard every point as a potential break-date $(T B)$ and run a regression for every possible break-date sequentially. From all possible break-points $(T B)$, the procedure selects as its choice of break-date $(T B)$ the date which minimizes the one-sided t-statistic for testing $\gamma=0$ against $\gamma<0$ [or $\gamma=(\varphi-1)<0$ ]. According to Zivot and Andrews, the presence of the end points cause the asymptotic distribution of the statistics to diverges towards infinity. Therefore, some region must be chosen such that the end points of the sample are not included. More recently, Sen (2003) showed that if one uses model $A$ and if the break occurs according to model $C$ then there would be a sizeable loss in power of the test. However, if break is characterized according to model $A$, but model $C$ is used then the loss in power is negligible, suggesting the superiority of model $\mathrm{C}$ over model A. While Zivot and Andrews (1992) and Perron (1997) determined the point of break 'endogenously' from the data, Lumsdaine and Papell (1997) suggested an improvement over the Zivot and Andrews (1992) model by incorporating a couple of structural breaks. However, such endogenous tests have been subject to criticism for their treatment of breaks under the null hypothesis. If the breaks are absent under the null hypothesis of unit root these tests may suggest evidence of stationarity with breaks (Lee and Strazicich, 2003). Lee and Strazicich (2003) on the other hand propose a two break minimum Lagrange Multiplier (LM) unit root test in which the alternative hypothesis unambiguously implies that the series is trend stationary.

\subsection{Toda - Yamamoto Modified Granger Causality under VAR Environment}

A simple definition of Granger Causality, in the case of two time-series variables, $X$ and $Y$ is as follows. " $X$ is said to Granger-cause $Y$ if $Y$ can be better predicted using the histories of both $X$ and $Y$ than it can by using the history of $Y$ alone." The absence of Granger causality can be tested by estimating the following VAR model (equations 2.4.1 and 2.4.2).

$$
\begin{aligned}
& y_{t}=\alpha+\sum_{i=1}^{p} \alpha_{i} y_{t-i}+\sum_{i=1}^{p} \beta_{i} x_{t-i}+u_{1 t} \\
& x_{t}=\beta+\sum_{i=1}^{p} \lambda_{i} y_{t-i}+\sum_{i=1}^{p} \delta_{i} x_{t-i}+u_{2 t}
\end{aligned}
$$

For the present study $y_{t}$ represents detrended real WPI for India and $x_{t}$ represents broad money supply or $\mathrm{G}$. $X$ does not Granger cause $Y$ is tested by $\mathrm{H}_{01}$ : $\beta_{1}=\beta_{2}=\cdots=\beta_{p}=0$ against the alternative that $\beta_{1} \neq \beta_{2} \neq \cdots \neq \beta_{p} \neq 0$. On the other hand $Y$ does not Granger cause $X$ is tested by $\mathrm{H}_{02}$ : $\lambda_{1}=\lambda_{2}=\cdots=\lambda_{p}=0$ against the alternative the $\lambda_{1} \neq \lambda_{2} \neq \cdots \neq \lambda_{p} \neq 0$. In each case rejection of null hypothesis implies the presence of Granger causality. The modified Wald test for testing Granger causality as proposed by Toda and Yamamoto (1995) avoids the problems associated with the usual Granger causality testing (which ignores non-stationarity and cointegrations between series while testing for causality). If the Wald test is being used to test linear restrictions on the parameters of a VAR model, and the data are non-stationary (which is most likely), then the Wald test statistic does not follow its usual asymptotic chi-square distribution under the null hypothesis (Toda and Yamamoto, 1995).

The approach to modified Granger causality as adopted in this study is outlined as follows. First, each time series variable is tested for stationarity (or for its order of integration) using standard tests such as ADF, PP and KPSS. The maximum order of integration $(m)$ for the group of time-series is determined. Structural breaks if any are identified and a structural break dummy variable is created. Second, a VAR model is set up in level, regardless of the orders of integration of the various time-series. None of the variables are differenced.

Third, the optimum lag length for each variable in the VAR, say $p$, is determined using $A I C, S I C, H Q$, or other usual statistics. Care is taken so that there is no serial correlation in the residuals. The length $p$ may be increased slightly until autocorrelation issues are resolved. Normality of the VAR residuals is highly desirable. Fourth, if both the time-series have the same order of integration, then Johansen Cointegration test is applied to test for co-integration (based on the selected VAR model). It provides some cross-check on the validity of the Causality results. Fifth, the favoured VAR model is constructed and additional $m$ lags of each variable are inserted into each equation. In EVIEWS 9 these new $m$ variables are to be treated as exogenous to the VAR system. The structural break dummy is also added (not shown) as an exogenous variable. It is thus ensured that the additional $m$ lags and the structural break dummy would not be dropped while testing for Granger noncausality (via the Wald tests). The new VAR is presented in equations 2.4.1(a) and 2.4.1 (b). 
$y_{t}=\alpha+\sum_{i=1}^{p} \alpha_{i} y_{t-i}+\sum_{j=p+1}^{p+m} \alpha_{j} y_{t-j}+$

$\sum_{i=1}^{p} \beta_{i} x_{t-i}+\sum_{j=p+1}^{p+m} \beta_{j} x_{t-j}+u_{1 t}$

$x_{t}=\beta+\sum_{i=1}^{p} \alpha_{i} y_{t-i}+\sum_{j=p+1}^{p+m} \alpha_{j} y_{t-j}+$

$\sum_{i=1}^{p} \beta_{i} x_{t-i}+\sum_{j=p+1}^{p+m} \beta_{j} x_{t-j}+u_{2 t}$

Finally, the hypothesis that the coefficients of only the first $p$ lagged values of $x$ are restricted to zero in the first equation (i.e. 2.4.1(a)), is tested using the standard Wald test (to test $\mathrm{H}_{01}$ : $x$ does not Granger cause $y$ ). Analogously, a similar procedure is followed (for equation 2.4.2(b)) to test that $y$ does not Granger cause $x$. The Wald statistic under the null hypothesis will be asymptotically distributed as chi-square with $p$ degrees of freedom. Importantly enough, if two or more time-series are cointegrated, then there must be Granger causality between them (either uni-directional or both ways). The converse however is not true. Thus causality may be present without co-integration. The follwing section presents empirical results of the study along with discussions.

According to Zapata and Rambaldi (1997) the advantage of using the Toda-Yamamoto procedure is that in order to test Granger causality in the VAR framework, it is not necessary to pre-test the variables for the integration and co-integration properties, provided the maximal order of integration of the process does not exceed the true lag length of the VAR model. According to Toda and Yamamoto (1995), Toda-Yamamoto procedure however does not substitute the conventional unit roots and co-integration properties pre-testing in time series analysis. They are considered as complimentary to each other.

\section{EMPIRICAL RESULTS AND ANALYSIS}

This section presents the empirical results of the study. For the purpose of choosing the appropriate detrended series for each time series variable both exponential and parabolic curves are first fitted to the data and the goodness of fit statistics of both are presented in the appendix (see Table A1). The EVIEWS reported values of $\mathrm{R}$-square, adjusted $\mathrm{R}$ square, AIC, SIC and $\mathrm{HQ}$ are presented for both models. It is evident that the exponential trend fit is a statistically better compared to the parabolic fit for each variable -WPI and broad money supply. This is by virtue of obtaining higher R-square and lower AIC, SIC and $H Q$ values in case of exponential trend fit. Thus the results in Table A1 suggest that exponential detrending should be preferred over quadratic or parabolic detrending. Hence the present study makes use of exponentially detrended data on each of the three variables.

Identification of structural breaks is of utmost importance. Table 1 presents the results of Bai-Perron test for unknown multiple structural break points of original vis-a-vis de-trended annual time series of selected variables. Interestingly, the detrended series exhibit single break points only.

For detrended variables the break points are single - at 2004 and 2002 respectively for WPI and M3. In other words there is a consistency in the time series behaviour of the detrended series of both real WPI and broad money supply. The original or non-detrended series on the other hand exhibits different as well as multiple break dates. The WPI exhibits significant breaks in 1990, 1996 and 2008. Interestingly no breaks in the original WPI series are observed during the plan holidays of the 1960s or just after nationalisation of banks. The first statistically significant break is found to occur at 1990, just before the onset of the period of liberalisation in India. The second break date in the original WPI series is 1996 . Finally the third break date in real WPI is found at 2008. Broad money supply exhibits two points of break, one at 1994 and the other at 2004.

Table 1: Bai-Perron Test for Unknown Multiple Structural Break Points of Original vis-a-vis De-trended Annual Time Series

\begin{tabular}{|c|c|c|}
\hline Variables & Break dates in Original Series & Break Dates in De-trended Series \\
\hline \hline WPI & $\mathbf{1 9 9 0 , 1 9 9 6 , 2 0 0 8}$ & $\mathbf{2 0 0 4}$ \\
\hline F-Statistic & $71.09,38.33,81.69$ & $\mathbf{2 0 0 2}$ \\
\hline M3 & $\mathbf{1 9 9 4 , 2 0 0 4}$ & 21.95 \\
\hline F-Statistic & $43.66,29.31$ & 2 \\
\hline
\end{tabular}

Source: Computed on the basis of original and exponentially detrended time series data for major macroeconomic indicators of India (1951-2013) taken from RBI: Handbook of Statistics on the Indian Economy, 2014. Notes: F-statistic values corresponding to each repatriation are presented below the break date series. 
Table 2: Structural Break Point Unit Root Test of De-Trended Series

\begin{tabular}{|c|c|c|c|c|}
\hline \multirow{2}{*}{ Variables } & \multicolumn{2}{|c|}{ ADF } & \multicolumn{2}{|c|}{ Zivot-Andrews } \\
\cline { 2 - 5 } & Level & $\mathbf{1}^{\text {st }}$ Diff. & Level & -4.015 \\
$\mathbf{1}^{\text {st }} \mathbf{D i f f .}$ \\
\hline \hline WPI & -2.760 & -7.649 & $(0.125,6)$ & $(<0.01,7)$ \\
& $(0.81,6)$ & $(<0.01,6)$ & 1991 & 1995 \\
\hline Break Date & 2004 & 1994 & -6.85 & NA \\
\hline M3 & -14.88 & NA & $(<0.01,4)$ & 2001 \\
\hline
\end{tabular}

Source: Estimated on the basis of secondary time series data on relevant variables (RBI: Handbook of Statistics on the Indian Economy, 2014) using EVIEWS 9 for Windows.

Notes: (i) Figures free of parenthesis in each cell are computed test statistic values. The first figure in parenthesis indicates $p$-value. For very small p-values (0.001, etc, exact $p$-values are not presented, instead $<0.01$ is used. (ii) The second figures in parenthesis indicate optimum lag length as selected by Schwartz's Criterion (automatic selection by the EVIEWS 9). (iii) A single unknown break date is selected by minimising the Dickey-Fuller t-Statistic automatically set in EVIEWS 9. (iv) M3 denotes broad money supply.

Stationarity testing is important from the point of view of knowing the order of integration of each time series variable. For example, if a time series is stationary not at level but at first difference then it follows an I(1) process. If a time series has a structural break the usual unit root test results (without incorporation of a break dummy) would be not only different, but would be misleading. Structural break point unit root tests are most appropriate under such circumstances. The structural break point unit root test results for detrended variables are shown in Table 2. WPI is found to be non-stationary at level but stationary at first difference according to both the ADF and ZivotAndrews tests. However the break dates are unidentical but close (1994 or 1995) at first difference. Detrended broad money supply is found to be stationary at level according to both tests. Both tests suggest a structural break point at 2001in case of broad money supply. EVIEWS 9 automatic optimum lag length selection option on the basis of Schwartz's Information Criterion is chosen while conducting these tests. The results in Table 2 reveals that detrended WPI and M3 are not integrated of the same order. Here the maximum order of integration is thus 1 .
The picture however is very different in Table $\mathbf{3}$ which presents the stationarity test results of original time series (non-detrended) ignoring structural breaks in each series. The ADF, PP and the KPSS test results are presented at level, first difference and second difference for each variable. In sharp contrast to the results in Table 2, none of the time series variables are stationary at level, at first difference or even at second difference (in case of M3). The KPSS test shows no stationarity at level, first difference, or second difference in case of M3 and WPI. In sum, the contrasting results observed in Tables 2 and $\mathbf{3}$ justifies the 'detrending of long run time series data' on the one hand and 'inclusion of structural break while testing for unit root' on the other.

After testing the structural break points and stationarity (i.e. unit roots), the vector auto regression (VAR) between broad money supply and WPI and consequently the modified Granger-Causality test results are presented and discussed. But first the optimum lag length for the VAR (i.e., the number of lagged regressors to be incorporated in the VAR - both WPI and broad money supply terms) needs to be

Table 3: Stationarity Tests of Original Time Series (Non-Detrended) Ignoring Structural Breaks in the Series

\begin{tabular}{|c|c|c|c|c|c|c|c|c|c|}
\hline \multirow[b]{2}{*}{ Variable } & \multicolumn{3}{|c|}{ ADF } & \multicolumn{3}{|c|}{ PP } & \multicolumn{3}{|c|}{ KPSS } \\
\hline & Level & $1^{\text {st }}$ Dif. & $2^{\text {nd }}$ Dif. & Level & $1^{\text {st }}$ Dif. & $2^{\text {nd }}$ Dif. & Level & $1^{\text {st }}$ Dif. & $2^{\text {nd }}$ Dif. \\
\hline M3 & $\begin{array}{c}6.759 \\
(0.999,6)\end{array}$ & $\begin{array}{c}4.999 \\
(0.999,6)\end{array}$ & $\begin{array}{c}-2.195 \\
(0.210,6)\end{array}$ & $\begin{array}{l}24.162 \\
(0.999)\end{array}$ & $\begin{array}{c}5.108 \\
(0.999)\end{array}$ & $\begin{array}{l}-6.058 \\
(<0.01)\end{array}$ & 0.635 & 0.635 & 0.694 \\
\hline WPI & $\begin{array}{c}2.15 \\
(0.99,8)\end{array}$ & $\begin{array}{c}-0.571 \\
(0.98,8)\end{array}$ & $\begin{array}{c}-3.023 \\
(0.136,7)\end{array}$ & $\begin{array}{c}4.82 \\
(0.999)\end{array}$ & $\begin{array}{c}-4.14 \\
(<0.01)\end{array}$ & $\mathrm{NC}$ & 0.255 & 0.379 & 0.444 \\
\hline
\end{tabular}

Source: Estimated on the basis of secondary time series data on relevant variables taken from RBI: Handbook of Statistics on the Indian Economy, 2014.

Notes: (i) First figures in each cell are computed test statistic values. The first figures in parenthesis in each cell indicate p-value. For very small p-values (smaller than 0.001, exact p-values are not presented, instead $<0.01$ is used. (ii) The second figures in parenthesis indicate optimum lag length as selected by Schwartz's Information Criteria (automatic selection by the EVIEWS-9). (iii) Asymptotic critical values of KPSS Test Statistic with trend and intercept: $1 \%=0.216 ; 5 \%=0.146$; $10 \%=0.119$. 'Null hypothesis' for KPSS test is that the time series variable is stationary (or does not have unit root). 
found. The EVIEWS 9 reported optimum lag length selection criteria results are presented in Table A2 of the appendix. Most criteria suggest that 4 endogenous lags must be chosen in the VAR model. According to Toda-Yamamoto (1995) approach however $(p+m)$ lags have to be incorporated in the VAR model where $m$ is the maximum order of integration of variables in the group. The $m$ additional lagged terms cannot be restricted to zero while testing for Granger-Causality for the Wald statistic to asymptotically follow a chisquare distribution. Apart from the intercept or constant, a structural break dummy variable is also included, the break date being taken as 2001 which is the break date for the detrended M3 series (the structural break dummy D_2001 assumes 0 for pre 2001 observations and assumes 1 for observations pertaining to 2001 and after). Since maximum order of integration in the group is 1 , an additional $5^{\text {th }}$ period lagged terms of both variables are introduced in the VAR as exogenous variables as per Toda-Yamamoto (1995) requirements.

The estimated results of the VAR between real WPI and broad money supply are presented in Table A3 of the appendix. The terms year and period are synonymous here. When WPI is the dependent variable, the 1 year lagged WPI significantly explains current year WPI. Rest of the lagged WPI coefficients are insignificant. More importantly, 1, 2 and 4 years lagged broad money supply terms are statistically significant in explaining current year WPI. When broad money supply is the dependent variable only the 1 year lagged WPI term is significant. R-square and adjusted R-square are both close to 99 percent implying that the VAR in Table $\mathbf{A} \mathbf{3}$ is in fact very well fit. The constant is insignificant in both models but the structural break dummy is statistically significant.

Before conducting Wald test for Granger Causality the statistical robustness of the VAR must be ensured. First, serial correlation if any must be eliminated from the VAR residuals. That is, VAR residuals must not be serially correlated and to this end the number of lagged endogenous regressors may have to be adjusted. Second, it is desirable that the VAR residuals be normal. Statistical testing and estimation based on nonnormal disturbances may be problematic. The residual serial correlation LM tests for the WPI - M3 VAR were conducted in EVIEWS and the results are presented in Table 4. Results in Table 4 reveal that at lags 1 and 2 respectively the LM statistic is significant at 5.8 percent but not at 5 percent. Otherwise it may safely inferred that serial correlation is absent in the VAR residuals till lag 10. The results of White's heteroscedasticity tests (table not presented) imply that the null hypothesis that VAR residuals are jointly heteroscedastic can be rejected only at 6.2 percent level of significance as the computed Chi-square value of 81.09 for 63 degrees of freedom has a $P$-value of 0.062 . In other words the homoscedasticity hypothesis may be accepted. The normality test results for the VAR residuals are shown in Table 5. The joint hypothesis of zero skewness is accepted. Similarly the joint hypothesis of a kurtosis of 3 is also accepted. Finally the p-value corresponding to the Jarque-Bera test statistic is high implying that the joint null hypothesis of normality of residuals is accepted.

Table 4: The Residual Serial Correlation LM Tests For the WPI - Broad Money Supply VAR

\begin{tabular}{|c|c|c|}
\hline Lags & LM-Stat & Prob \\
\hline \hline 1 & 9.127 & 0.058 \\
\hline 2 & 9.147 & 0.058 \\
\hline 3 & 2.642 & 0.619 \\
\hline 4 & 1.521 & 0.823 \\
\hline 5 & 8.707 & 0.069 \\
\hline 6 & 6.914 & 0.141 \\
\hline 7 & 4.492 & 0.344 \\
\hline 8 & 8.200 & 0.085 \\
\hline 9 & 8.086 & 0.088 \\
\hline 10 & 9.020 & 0.061 \\
\hline
\end{tabular}

Source: Estimated from secondary data compiled from RBI: Handbook of Statistics on the Indian Economy, 2014. The results as generated under the post VAR option of Residual Tests in EVIEWS 9.

The Wald tests for Granger non-causality, tests for zero parameter restrictions on the coefficients of the lagged endogenous variables of the VAR model. However the exogenous variables are not dropped. The Wald test results of Granger non-causality between WPI and M3 are presented in Table 6 . The first null hypothesis that M3 does not Granger-cause WPI is rejected at less than 0.1 percent. Thus the alternative that M3 causes WPI is accepted. The second null hypothesis that WPI does not Grangercause $G$ is accepted at 16.89 percent. Hence M3 Granger causes WPI but the converse is not true. In other words there is uni-directional causality between M3 and WPI and runs from M3 to WPI. So monetary expansion in India is found to have a positive influence on WPI, but whether this expansionary policy is independent or triggered due to fiscal factors is beyond the scope of the present study. 
Table 5: The WPI-Broad Money Supply VAR Model: Normality Test of Residuals

\begin{tabular}{|c|c|c|c|c|}
\hline \multicolumn{5}{|c|}{ Method of Orthogonalization: Cholesky (Lutkepohl) } \\
\hline \multicolumn{5}{|c|}{ Null Hypothesis: Residuals Are Multivariate Normal } \\
\hline Component & Skewness & Chi-sq & df & P-value \\
\hline 1 & -0.3349542 & 1.009749 & 1 & 0.315 \\
\hline 2 & 0.4184673 & 1.576034 & 1 & 0.209 \\
\hline Joint & & 2.585783 & 2 & 0.274 \\
\hline Component & Kurtosis & Chi-sq & df & P-value \\
\hline 1 & 2.436645 & 0.714079 & 1 & 0.398 \\
\hline 2 & 1.837485 & 3.040743 & 1 & 0.081 \\
\hline Joint & & 3.754822 & 2 & 0.153 \\
\hline Component & \multicolumn{2}{|c|}{ Jarque-Bera Stat } & df & P-value \\
\hline 1 & \multicolumn{2}{|c|}{1.723828} & 2 & 0.422 \\
\hline 2 & \multicolumn{2}{|c|}{4.616777} & 2 & 0.099 \\
\hline Joint & \multicolumn{2}{|c|}{7.579983} & 4 & 0.108 \\
\hline
\end{tabular}

Source: Estimated from secondary data compiled from RBI: Handbook of Statistics on the Indian Economy, 2014. Notes: The results are EVIEWS 9 generated under the post VAR option of Residual Tests. The figures as reported in EVIEWS output sheet are exactly reproduced.

Table 6: Wald Tests for Granger Causality between M3 and WPI (Included Observations: 54)

\begin{tabular}{|c|c|c|c|c|}
\hline Null Hypothesis & Chi-sq & df & P-value & Inference \\
\hline \hline (i) M3 does not Granger Cause WPI & 16.335 & 4 & 0.003 & Reject Null Hypothesis \\
\hline (ii) WPI does not Granger Cause M3 & 8.068 & 4 & 0.089 & Accept Null Hypothesis \\
\hline
\end{tabular}

Source: Estimated from secondary data compiled from RBI: Handbook of Statistics on the Indian Economy, 2014. Notes: The results are EVIEWS 9 generated under the post VAR option of Lag Structure. G represents broad money supply. The $2^{\text {nd }}$ null hypothesis implies absence of Wagner's Law.

The Johansen Co-integration test between WPI and broad money supply are presented in Table 7 . Clearly the trace test and maximum eigen value test indicates 1 co-integrating vector each between real WPI and M3 implying thereby that there is a long run equilibrium relationship between real WPI and broad money supply in India over the period 1951-2013. This is somewhat unexpected in view of the fact that exponentially detrended M3 and WPI were not found to be integrated of the same order. Both structural break point ADF and Zivot-Andrews tests suggest that M3 is $I(0)$ (stationary at level) while WPI is I(1) (stationary at first difference), both having different break dates. It may finally be argued however that the long-run co-integrating or equilibrium relationship between broad money supply and whole-sale price index justifies the causality results obtained earlier.

\section{SUMMARY AND CONCLUSIONS}

The present study has tested for short run causality between broad money supply and WPI in India during
1951-2013 adopting the Toda-Yamamoto (1995) modified Granger causality approach under a VAR environment. Exponentially detrended annual time series data on WPI and broad money supply are used for this purpose. Bai-Perron tests for structural breaks of the detrended data series reveal significant breaks in the variables around the period 1990-2001. The findings are suggestive of a uni-directional causality from broad money supply to WPI. Further both real WPI and broad money supply have a long-run cointegrating relationship. Hence short run causal relations may exist.

But to a certain extent monetary expansion in India is not independent of fiscal expansion. In India burgeoning fiscal deficits have led to increased government borrowing from the RBI mainly to finance revenue deficits and capital expenditure. Unfortunately in developing countries like India supply mechanisms are inflexible and as such sudden injections of money raise demand but due to supply stickiness, output does not respond quick enough resulting in price rise and 
Table 7: Johansen Co-integration Test between M3 and WPI

\begin{tabular}{|c|c|c|c|c|}
\hline \multicolumn{4}{|c|}{ Unrestricted Cointegration Rank Test (Trace) } & \multirow[b]{2}{*}{ P-value ** } \\
\hline $\begin{array}{l}\text { Hypothesized } \\
\text { No. of CE(s) }\end{array}$ & Eigenvalue & $\begin{array}{c}\text { Trace } \\
\text { Statistic }\end{array}$ & $\begin{array}{c}0.05 \\
\text { Critical Value }\end{array}$ & \\
\hline None * & 0.629547 & 57.393010 & 17.99296 & 0 \\
\hline At most 1 & 0.006437 & 0.368148 & 3.756954 & 0.5501 \\
\hline
\end{tabular}

Trace test indicates 1 cointegrating eqn(s) at the 0.05 level.

*denotes rejection of the hypothesis at the 0.05 level.

${ }^{* *}$ MacKinnon-Haug-Michelis (1999) p-values.

\begin{tabular}{|c|c|c|c|c|}
\hline \multicolumn{5}{|c|}{ Unrestricted Cointegration Rank Test (Maximum Eigenvalue) } \\
\hline Hypothesized & & Max-Eigen & $\mathbf{0 . 0 5}$ & P-value ** \\
\hline No. of CE(s) & Eigenvalue & Statistic & Critical Value & 0 \\
\hline \hline None * & 0.635768 & 57.588341 & 16.77044 & 0.5383 \\
\hline At most 1 & 0.006501 & 0.371786 & 3.756954 & \\
\hline
\end{tabular}

Max-eigenvalue test indicates 1 cointegrating eqn(s) at the 0.05 level.

*denotes rejection of the hypothesis at the 0.05 level.

${ }^{* *}$ MacKinnon-Haug-Michelis (1999) p-values.

Source: Estimated from secondary data compiled from RBI: Handbook of Statistics on the Indian Economy, 2014. Notes: The results are EVIEWS 9 generated and are not rounded off.

inflation. To further validate the results of the present study both structural VAR and ARDL approaches need to be separately undertaken. Furthermore it has to be investigated using the same approach whether deficit

\section{APPENDIX}

\section{Selected Tables}

Table A1: Comparing Goodness of Fit Statistics of Parabolic Trend Fitting vis-s-vis Exponential Trend Fitting for each Time Series Variable for the period 1951-2013

\begin{tabular}{|c|c|c|c|c|}
\hline \multirow{2}{*}{ Variables } & \multicolumn{2}{|c|}{ Parabolic Trend Fitting } & \multicolumn{2}{c|}{ Exponential Trend Fitting } \\
\cline { 2 - 5 } & $\mathbf{R}^{2}$;Adj.R & AIC;SIC;HQ & $\mathbf{R}^{2}$;Adj.: ${ }^{2}$ & AIC;SIC;HQ \\
\hline \hline WPI & $0.955 ; 0.936$ & $27.19 ; 27.28 ; 27.23$ & $0.978 ; 0.954$ & $-1.32 ;-1.25 ;-1.29$ \\
\hline M3 & $0.969 ; 0.945$ & $36.21 ; 36.29 ; 36.24$ & $0.988 ; 0.979$ & $-2.22 ;-2.13 ;-2.17$ \\
\hline
\end{tabular}

Source: Computed on the basis of secondary time series data compiled from RBI: Handbook of Statistics on the Indian Economy, 2014.

Table A2: Optimum Lag Length Selection in the M3-WPI VAR Model

\begin{tabular}{|c|c|c|c|c|c|c|}
\hline Lag & LogL & LR & FPE & AIC & SC & HQ \\
\hline \hline 0 & -1487.52 & NA & $5.37 \mathrm{E}+20$ & 55.24689 & 55.39947 & 55.30574 \\
\hline 1 & -1361.47 & 233.4434 & $6.85 \mathrm{E}+18$ & 50.73146 & 51.03642 & 50.84906 \\
\hline 2 & -1333.71 & 49.35273 & $2.95 \mathrm{E}+18$ & 49.85658 & 50.31403 & 50.03304 \\
\hline 3 & -1324.88 & 15.02708 & $2.51 \mathrm{E}+18$ & 49.68321 & 50.29325 & 49.91852 \\
\hline 4 & -1315.37 & $12.82616^{*}$ & $1.8 \mathrm{E}+18^{*}$ & $49.33205^{*}$ & $50.24664^{*}$ & 49.77818 \\
\hline 5 & $-1307.12^{*}$ & 15.50923 & $2.07 \mathrm{E}+18$ & 49.48412 & 50.24705 & $49.68496^{*}$ \\
\hline
\end{tabular}

Source: Estimated on the basis of Secondary Data compiled from RBI: Handbook of Statistics on the Indian Economy, 2014. Results are EVIEWS 9 generated. Notes: * indicates lag order selected by the criterion

LR: sequential modified LR test statistic (each test at $5 \%$ level)

FPE: Final prediction error

AIC: Akaike information criterion

SC: Schwarz information criterion

HQ: Hannan-Quinn information criterion 
Table A3: Estimated VAR between M3 and WPI

\begin{tabular}{|c|c|c|}
\hline & M3 & WPI \\
\hline \multirow[t]{3}{*}{ M3 (-1) } & 1.31188 & 0.39175 \\
\hline & 0.20108 & 0.12072 \\
\hline & [6.52420] & [3.24521] \\
\hline \multirow[t]{3}{*}{ M3 (-2) } & -0.42797 & 0.01177 \\
\hline & 0.24861 & 0.14925 \\
\hline & {$[-1.72148]$} & {$[0.07886]$} \\
\hline \multirow[t]{3}{*}{ M3 (-3) } & 0.34847 & 0.09090 \\
\hline & 0.25416 & 0.15257 \\
\hline & [1.37109] & [ 0.59573] \\
\hline \multirow[t]{3}{*}{ M3 (-4) } & -0.02373 & -0.20346 \\
\hline & 0.28042 & 0.16835 \\
\hline & {$[-0.08462]$} & {$[-1.20858]$} \\
\hline \multirow[t]{3}{*}{ WPI (-1) } & 0.59349 & 1.31506 \\
\hline & 0.24134 & 0.21263 \\
\hline & [2.45916] & [6.18474] \\
\hline \multirow[t]{3}{*}{ WPI (-2) } & 1.77065 & -0.03419 \\
\hline & 0.48406 & 0.29060 \\
\hline & [3.65794] & {$[-0.11767]$} \\
\hline \multirow[t]{3}{*}{ WPI (-3) } & -0.49203 & -0.35157 \\
\hline & 0.52496 & 0.31515 \\
\hline & {$[-0.93727]$} & {$[-1.11554]$} \\
\hline \multirow[t]{3}{*}{ WPI (-4) } & 1.41886 & -0.19121 \\
\hline & 0.53821 & 0.32311 \\
\hline & [2.63625] & {$[-0.59177]$} \\
\hline \multicolumn{3}{|c|}{ Exogenous Variables } \\
\hline \multirow[t]{3}{*}{$\mathrm{c}$} & -5.93778 & 8.87366 \\
\hline & 10.092 & 6.058 \\
\hline & {$[-0.58836]$} & [ 1.46471] \\
\hline \multirow[t]{3}{*}{ d_2001 } & 7.712 & 2.478 \\
\hline & 2.396 & 1.339 \\
\hline & [ 3.21873$]$ & [ 1.85132$]$ \\
\hline \multirow[t]{3}{*}{ M3 (-5) } & -0.04639 & -0.18993 \\
\hline & 0.20952 & 0.12578 \\
\hline & {$[-0.22143]$} & {$[-1.50995]$} \\
\hline \multirow[t]{3}{*}{ WPI (-5) } & -0.84891 & 0.03395 \\
\hline & 0.36927 & 0.22169 \\
\hline & {$[-2.29890]$} & [ 0.15315$]$ \\
\hline R-squared & 0.94422 & 0.94937 \\
\hline Adj. R-quared & 0.94145 & 0.94792 \\
\hline F-Statistic & 325.64687 & 625.02831 \\
\hline Log-likelihood & -633.09312 & -606.29032 \\
\hline Akaike AIC & 23.43832 & 22.46367 \\
\hline Schwarz SC & 23.85659 & 22.88194 \\
\hline
\end{tabular}

Source: Estimated on the basis of Secondary data on relevant variables compiled from RBI: Handbook of Statistics of the Indian Economy, 2014. Estimations are done using EVIEWS 9 for Windows.

Notes: The figures as reported in EVIEWS output sheet are exactly reproduced in table 6 without rounding off. The structural break dummy (for 2004) and the two $5^{\text {th }}$ period lagged terms of both variables are exogenous to the VAR system. The Granger Causality or Block Exogeneity Wald Tests imply zero parameter restrictions only the endogenous lagged terms i.e., on lag 1 to 4 only. 


\section{REFERENCES}

Bai J. 1997. "Estimating Multiple Breaks One at a Time." Econometric Theory. 13: 315-52. http://dx.doi.org/10.1017/S0266466600005831

Bai J. and P. Perron. 1998. "Estimating and Testing Linear Models with Multiple Structural Changes." Econometrica. 66:47-78. http://dx.doi.org/10.2307/2998540

Bai J. and P. Perron. 2003a. "Computation and Analysis of Multiple Structural Change Models." Journal of Applied Econometrics. 18: 1-22.

http://dx.doi.org/10.1002/jae.659

Bai J. and P. Perron. 2003b. "Critical Values for Multiple Structural Change Tests." Econometrics Journal. 6:72-78. http://dx.doi.org/10.1111/1368-423X.00102

D"Souza E. 2003. "What is Monetary Policy Doing?" Economic and Political Weekly. 38 (8): 821-23.

Jadhav W. and B. Singh. 1990. "Fiscal Monetary Dynamics Nexus in India: An Econometric Model." Economic and Political Weekly. 25(3):159-165.

Kwiatkowski D., Phillips P. C. B., Schmidt P. and Y. Shin. 1992. "Testing the Null Hypothesis of Stationarity against an Alternative of a Unit Root: How Sure Are We that Economic Time Series Have a Unit Root?" Journal of Econometrics, 54:159-78 http://dx.doi.org/10.1016/0304-4076(92)90104-Y

Lee J. and M.C. Strazicich. 2003. "Minimum LM Unit Root Test with Two Structural Breaks." Review of Economics and Statistics. 63:1082- 89. http://dx.doi.org/10.1162/003465303772815961

Lumsdaine R. L and. D. H. Papell. 1997. "Multiple Trend Breaks and the Unit Root Hypothesis." Review of Economics and Statistics. 79(2): 212-18. http://dx.doi.org/10.1162/003465397556791

Mishra A. and V. Mishra. 2009. "Preconditions for Inflation Targeting in an Emerging Economy: The Case of India." DRU Working Paper No. DEVDP 09-08. Development Research Unit. Monash University.

Mohan R. 2008. "Monetary Policy Transmission in India." BIS Paper 35:259-307.

Parida P.C., Mallick, H.and M. K. Mathiyazhagan. 2001. "Fiscal Deficits, Money Supply and Price Level: Empirical Evidence from India." Journal of Indian School of Political Economy. 13( 4 Oct-Dec): 583-93.
Pattnaik R.K. and A.Samantaraya. 2006. "Indian Experience of Inflation - A Review of the Evolving Process." Economic and Political Weekly. 41(4Jan): 356-63.

Perron P. 1989. "The great crash, the oil price shock and the unit root hypothesis." Econometrica. 57(6):1361-1401. http://dx.doi.org/10.2307/1913712

Perron P. 1997. "Further Evidence on Breaking Trend Functions in Macroeconomic Variables." Journal of Econometrics. 80(2): 355-85. http://dx.doi.org/10.1016/S0304-4076(97)00049-3

Phillips P. and P. Perron. 1988. "Testing for a Unit Root in Time Series Regression." Biometrica. 75:335-46. http://dx.doi.org/10.1093/biomet/75.2.335

Rangarajan C. and R.R. Arif. 1990. "Money, Output and Prices: A Macroeconomics Model." Economic and Political Weekly. 25(16):837-52.

Rangarajan C. 2001. "Some Critical Issues in Monetary Policy." Economic and Political Weekly. 36(24): 2139-2146.

Reddy Y.V. 1999. "Inflation in India: Status and Issues." in Reddy Y.V. 2000: Monetary and Financial Sector Reforms in India: A Central Bankers' perspective. UBS Publishers Distributors Ltd. New Delhi.

Sen A. 2003. "On Unit Root Tests When the Alternative is a Trend Break Stationary Process." Journal of Business and Economic Statistics. 21:174-84. http://dx.doi.org/10.1198/073500102288618874

Singh K. and K.P. Kalirajan. 2006. "Monetary Policy in India: Objectives, Reaction Function and Policy Effectiveness." Review of Applied Economics. 2(2):181-199.

Singh K. and K.P.Kalirajan. 2007. "Monetary Transmission in the Post-Reform India: An Evaluation." Journal of the Asia Pacific Economy. 12(2):158-87. http://dx.doi.org/10.1080/13547860701252371

Srimany A. K. and G. P. Samanta. 1998. "Identification of monetary policy shocks and its effects on output and price: A Structural VAR approach." RBI Occasional Papers.19(2):109-28.

Toda H.Y. and T. Yamamoto. 1995. "Statistical Inference in Vector Autoregressions with Possibly Integrated Processes." Journal of Econometrics. 66(1-2): 225-50. http://dx.doi.org/10.1016/0304-4076(94)01616-8

Zivot E. and K. Andrews. 1992. "Further Evidence on the Great Crash, the Oil Price Shock, and the Unit Root Hypothesis." Journal of Business and Economic Statistics. 10(10): 251270.

\section{DOI: http://dx.doi.org/10.6000/1929-7092.2016.05.13}

(c) 2016 Debnath and Mazumder; Licensee Lifescience Global.

This is an open access article licensed under the terms of the Creative Commons Attribution Non-Commercial License (http://creativecommons.org/licenses/by-nc/3.0/) which permits unrestricted, non-commercial use, distribution and reproduction in any medium, provided the work is properly cited. 